\title{
Effects of prolonged photoperiod on growth performance, serum lipids and meat quality of Jinjiang cattle in winter
}

\author{
Yan $\mathrm{Yu}^{1}$, Jingyun Qiu ${ }^{1}$, Jincheng Cao ${ }^{1}$, Yingying Guo ${ }^{1}$, Hui Bai ${ }^{1}$, Shengjuan Wei ${ }^{1}$, and Peishi Yan ${ }^{1}$ **
}

* Corresponding Author: Peishi Yan Tel: +86-25-84399068, Fax: +86-25-84399068,

E-mail:yanps@hotmail.com

${ }^{1}$ Department of Animal Science and Technology, Nanjing Agricultural University, Nanjing 210095, China

ORCID

Yan Yu

https://orcid.org/0000-0002-2208-0983

Jingyun Qiu

https://orcid.org/0000-0002-4064-8210 Jincheng Cao

https://orcid.org/0000-0001-8032-7393

Yingying Guo

https://orcid.org/0000-0003-2188-7299

Hui Bai

https://orcid.org/0000-0002-0827-3519

Shengjuan Wei

https://orcid.org/0000-0001-7340-8208

Peishi Yan

https://orcid.org/0000-0003-1723-8632

Submitted Oct 30, 2020; Revised Dec 26, 2020; Accepted Feb 2, 2021
Objective: This study was conducted to investigate the potential effects of prolonged photoperiod on the serum lipids, carcass traits, and meat quality of Jinjiang cattle during winter. Methods: Thirty-four Jinjiang bulls aged between 14 and 16 months were randomly assigned to two groups that were alternatively subjected to either natural daylight $+4 \mathrm{~h}$ supplemental light (long photoperiod, LP) or natural daylight (natural photoperiod, NP) for 96 days. The potential effects on the levels of serum lipids, carcass traits, meat quality, and genes regulating lipid metabolism in the intramuscular fat (IMF) of the cattle were evaluated.

Results: Jinjiang cattle kept under LP showed significant increase in both dry matter intake and backfat thickness. the serum glucose and the plasma leptin levels were significantly reduced, while that of melatonin and insulin were observed to be increased. The crude fat contents of biceps femoris muscle and longissimus dorsi muscle were higher in LP than in NP group. In longissimus dorsi muscle, the proportions of C17:0 and C18:0 were significantly higher but that of the C16:1 was found to be significantly lower in LP group. The relative mRNA expressions in IMF of longissimus dorsi muscle, the lipid synthesis genes (proliferatoractivated receptor gamma, fatty acid-binding protein) and the fatty acid synthesis genes (acetyl-coa carboxylase, fatty acid synthetase, 1-acylglycerol-3-phosphate acyltransferase) were significantly up-regulated in LP group $(\mathrm{p}<0.05)$; whereas the hormone-sensitive lipase and stearoyl-CoA desaturase 1 were significantly down-regulated in LP than in NP group.

Conclusion: Prolonged photoperiod significantly altered the growth performance, hormonal levels, gene expression and fat deposition in Jinjiang cattle. It suggested that the LP improved the fat deposition by regulating the levels of different hormones and genes related to lipid metabolism, thereby improving the fattening of Jinjiang cattle during winter.

Keywords: Gene Expression; Jinjiang Cattle; Meat Quality; Photoperiod; Serum Lipids

\section{INTRODUCTION}

Jinjiang cattle, a breed indigenous to China with zebu lineages, and revered for their great tolerance to roughage, have been reported to display excellent resistance to heat stress and provide a desirable meat quality $[1,2]$. However, Jinjiang cattle are relatively smaller in size and grow relatively slowly during winter [3].

In recent years, studies on fat deposition in Jinjiang cattle mainly focused on nutritional regulation [4], However, photoperiod management has been extensively tried to improve growth or production performance in domestic animals. Pigs in a long photoperiod (LP) group showed a greater live weight and carcass weight as compared to a short photoperiod (SP) group [5]. Moreover, the breasts from the boilers subjected to $23 \mathrm{~L}: 1 \mathrm{D}$ and $16 \mathrm{~L}: 8 \mathrm{D}$ had the greatest content of fat [6]. These results suggested that exposure to a prolonged photoperiod could influence lipid metabolism and production performance in different animals. 
In ruminants, photoperiod management can be used to improve heifer growth and maximize accretion of lean tissue, including mammary parenchyma [7]. Steers in nature photoperiod (NP) produced fatter carcasses than those on LP, and heifers on NP deposited more fatty tissue between autumn and winter and less between winter and spring compared with those on LP [8]. In addition, LPs during established lactation increased milk production in dairy cattle and dairy sheep [9-13]. However Some researchers have found that compared with NP, short-day photoperiod during lactation significantly increased daily milk yield in goats and cows [14], Moreover, many scholars pointed out that the photoperiod manipulation on milk yield and milk composition were associated with mammary development and hormone changes $[15,16]$.

Although several previous studies have extensively described the responses of physiological functions, energy metabolism and production performance of different mammals exposed to photoperiod manipulation, there is only limited information available on the photoperiod responses of beef cattle. Therefore, the effect of prolonged photoperiod on growth performance of Jinjiang cattle is worth exploring. In this study, the carcass characteristics, meat quality and gene expression under different photoperiods in Jinjiang bulls was evaluated. This study provides a certain scientific basis for photoperiod management of Jinjiang cattle in winter.

\section{MATERIALS AND METHODS}

\section{Ethics statement}

The care and use of animals followed Animal Research Institute Committee guidelines of Nanjing Agriculture University, China. This study has been approved by the Committee of the Animal Research Institute of Nanjing Agriculture University, China (SYXK2011-0036).

\section{Animals and light time}

The experiment was carried out during November 8, 2017 to February 12, 2018 in Gao 'a national beef cattle system high safety test station located in Jiangxi Province (lat. $24^{\circ}$ $29^{\prime}$ to $30^{\circ} 04^{\prime} \mathrm{N}$ and $113^{\circ} 34^{\prime}$ to $118^{\circ} 28^{\prime} \mathrm{E}$ ) and maintained at a range of $-3^{\circ} \mathrm{C}$ to $17^{\circ} \mathrm{C}$. A total of 34 Jinjiang bulls, aged 14 to 16 months-with body weights of $276.93 \pm 6.83 \mathrm{~kg}$, were randomly divided into two groups. The control group continuously received the NP (12 h light from 0500 to 1700 and $12 \mathrm{~h}$ darkness); the treatment group received LP (16 h light from 0500 to 2100 and $8 \mathrm{~h}$ darkness). The two groups of cattle were housed in two semi-enclosed sheds and were fed and watered ad libitum under the normal conditions. The animals were acclimated to the experimental condition for 7 days prior to the start of the experiments. The whole experimental period lasted for a total of 96 days. The composition and nutrient levels of the basal diet is provided in Table 1.

\section{Blood sampling and analysis}

The blood was collected once a week before the end of the experiment and at $4 \mathrm{~h}$ intervals. All the plasma samples were run in duplicate in a single assay. The plasma levels of glucose (Glu), total cholesterol (TC), low-density triglycerides (TG), non-esterified fatty acids (NEFA), high-density lipoproteins, low-density lipoprotein, and apolipoproteins (A1, B, E) were individually measured at the Clinical Biochemistry Service of Nan Jing general hospital (Nanjing, China), using Beckman AU5811 analyzer (Beckman- Coulter, 250S.Kraemer Boulevard Brea, USA). The plasma melatonin level was determined using high performance liquid chromatography (HPLC, Thermo Ultimate 3000; Thermo Fisher Scientific, Waltham, MA, USA) as described previously by Yin et al [16]. Leptin and insulin levels were measured in plasma using commercial bovine ELISA kit (Shanghai Enzyme-linked Biotechnology, Shanghai, China) according to the manufacturer's instructions. For plasma insulin analysis, the results with intra-assay coefficient of variation (CV) of 3.0\% to $6.0 \%$ were taken into consideration. For leptin analysis, results were acceptable with a CV of less than $5 \%$.

\section{Meat sample collection and quality determination}

At the end of the experiment, six cattle were randomly selected from each group for slaughter. The animals were weighed and transported to a meat processing plant where they were kept in individual boxes with access to water for $12 \mathrm{~h}$. The backfat thickness and eye muscle area was determined by ultrasonic (Liaoning Hande B ultrasound HD9300A; Dandong, China). The animals were stunned before slaughter. The carcasses were dressed and cut along the spine into two half-carcasses that were chilled for $45 \mathrm{~min}$ at $4^{\circ} \mathrm{C}$. The meat quality and nutrient content of Jinjiang cattle was

Table 1. Composition and nutrient levels of diet (DM basis)

\begin{tabular}{|c|c|c|c|}
\hline Ingredient & Percentage & Nutrients & Content \\
\hline Soybean meal & 3.08 & $\mathrm{NE}(\mathrm{MJ} / \mathrm{kg})^{2)}$ & 2.74 \\
\hline Brewers grains & 75.13 & DM (\%) & 45.81 \\
\hline Corn & 13.67 & $\mathrm{CP}(\%)$ & 8.57 \\
\hline Straw & 5.55 & EE $(\%)$ & 5.26 \\
\hline Premix ${ }^{11}$ & 1.93 & $\operatorname{NDF}(\%)$ & 47.33 \\
\hline Sodium bicarbonate & 0.39 & $\operatorname{ADF}(\%)$ & 23.92 \\
\hline Salt & 0.25 & & \\
\hline Total & 100 & & \\
\hline
\end{tabular}

DM, dry matter; NE, net energy; CP, crude protein; EE, ether extract; NDF, neutral detergent fiber; $A D F$, acid detergent fiber.

${ }^{1)}$ Ingredients of premix: vitamin $\mathrm{A} 250,000 \mathrm{U}$, vitamin $\mathrm{D}_{3} 40,000 \mathrm{U}$, vitamin E 1,000 U, Cu $\left(\mathrm{CuSO}_{4} 5 \mathrm{H}_{2} \mathrm{O}\right) 1 \mathrm{~g} / \mathrm{kg}$, Fe $\left(\mathrm{FeSO}_{4} 7 \mathrm{H}_{2} \mathrm{O}\right) 5 \mathrm{~g} / \mathrm{kg}$, $\mathrm{Mn}$ $\left(\mathrm{MnSO}_{4} \mathrm{H}_{2} \mathrm{O}\right) 4 \mathrm{~g} / \mathrm{kg}, \mathrm{Zn}\left(\mathrm{ZnSO}_{4} 7 \mathrm{H}_{2} \mathrm{O}\right) 3 \mathrm{~g} / \mathrm{kg}$, Se $\left(\mathrm{Na}_{2} \mathrm{SeO}_{3}\right) 0.01 \mathrm{~g} / \mathrm{kg}, \mathrm{I}(\mathrm{KI})$ $0.05 \mathrm{~g} / \mathrm{kg}$, Co $\left(\mathrm{CoSO}_{4} 7 \mathrm{H}_{2} \mathrm{O}\right) 0.01 \mathrm{~g} / \mathrm{kg}$, and $\mathrm{Mg}\left(\mathrm{MgSO}_{4}\right) 50 \mathrm{~g} / \mathrm{kg}$.

${ }^{2)}$ Calculated value 
determined based on the method previously described by Zheng [17]. The samples from longissimus dorsi muscle (LDM) and biceps femoris muscle (BFM) were collected and stored at $-20^{\circ} \mathrm{C}$ until further analysis. All slaughter and post slaughter processes were carried out in accordance with the current meat industry regulations.

\section{Fatty acid composition}

One hundred milligram intramuscular fat (IMF) from LDM were prepared and extracted in chloroform: methanol (2:1, $\mathrm{vol} / \mathrm{vol}$ ), and non-adecanoic acid (N5252, 646-30-0; SigmaAldrich, St. Louis, MO, USA) was added as an internal standard. After methylation $(\mathrm{NaOH} / \mathrm{MeOH}$ followed by $\mathrm{HCl} / \mathrm{MeOH}$ ), the fatty acids and thirty-seven standard fatty acid methyl esters (C13-CRM47885; Sigma-Aldrich, USA) were analyzed on gas chromatograph (Agilent 7890A, New York, USA) with a CP-Sil 88 column $(100 \mathrm{~m} \times 0.25 \mathrm{~mm} \times 0.2$ $\mathrm{mm})$. The split ratio was $1: 10$. The oven temperature was maintained at $140^{\circ} \mathrm{C}$ for $2 \mathrm{~min}$, and increased to $180^{\circ} \mathrm{C}$ at a rate of $1.5^{\circ} \mathrm{C} / \mathrm{min}$ and maintained at $180^{\circ} \mathrm{C}$ for $10 \mathrm{~min}$, and then increased to $240^{\circ} \mathrm{C}$ by $4^{\circ} \mathrm{C}$ and thereafter maintained at $240^{\circ} \mathrm{C}$ for $20 \mathrm{~min}$.

\section{Relative mRNA expression analysis}

The total RNA was extracted from IMF using Trizol Reagent as per the manufacturer's instructions. The purity and concentration of total RNA were measured using a spectrophotometer
(Nanodrop 2000; Thermo Fisher, USA) at 260 and $280 \mathrm{~nm}$. The ratios of absorption $(260 / 280 \mathrm{~nm})$ of all samples were observed to be between 1.8 and 2.0. RNA was further treated with RNase-free DNase 1 to carefully remove contaminating genomic DNA. Total RNA was reverse transcribed to cDNA ( $10 \mu \mathrm{L}$ reaction system was applied for $500 \mathrm{ng}$ of total RNA) using a Prime Script RT Master Mix kit. Real-time polymerase chain reaction (PCR) was carried out in an optical 96-well plates on an ABI 7500 Real-Time PCR System (Applied Biosystems, Foster City, CA, USA) using SYBR Premix Ex Taq kits. The reagents used in this process were obtained from Takara Biotechnology Co. Ltd., Dalian, China. The list of primers used for real-time PCR assay have been presented in Table 3 and the primers were synthesized by BGI (Beijing Genomics Institution, Beijing, China). All the primers used in this study are listed in Table 2 . The $2^{-\Delta \Delta \mathrm{Ct}}$ method was used to analyze the relative changes in the gene expression after normalization against $18 \mathrm{~S}$ ribosomal RNA used as an internal control.

\section{Statistical analysis}

The data has been expressed as the mean \pm standard error of the mean. Statistical analyses was performed using SPSS Statistics 22 (SPSS, Inc., Chicago, IL, USA). Student's t-test was generally employed for single sample sets statistical comparisons. The level of statistical significance was set bilaterally at $5 \%$.

Table 2. Sequences of primers used in quantitative polymerase chain reaction

\begin{tabular}{|c|c|c|c|c|}
\hline Gene & GenBank ID & Forward primer sequence ( $5^{\prime}$ to $\left.3^{\prime}\right)$ & Reverse primer sequence ( $5^{\prime}$ to $\left.3^{\prime}\right)$ & Product size (bp) \\
\hline PPAR Y & NM_181024.2 & TGGAGACCGCCCAGGTTTGC & AGCTGGGAGGACTCGGGGTG & 111 \\
\hline FABP4 & NM_174314.2 & TCCTTCAAATTGGGCCAGGAA & CCCTTGGCTTATGCTCTCTCA & 218 \\
\hline$C / E B P a$ & NM_176784.2 & TGGGCAAGAGCCGGGACAAG & ACCAGGGAGCTCTCGGGCAG & 166 \\
\hline$H S L$ & NM_001080220.1 & ATTGCCGACTTCCTACGAGA & AGTCCGATGGAGATGGTCTG & 119 \\
\hline ATGL & FJ897536.1 & TCTGCCTGCTGATTGCTATG & GGCCTGGATAAGCTCCTCTT & 121 \\
\hline FASN & NM_001012669 & GGTGCGTCCTGGTGTCTAA & CCTCGGGTGAGGACATTTAT & 85 \\
\hline ACACA & AJ132890 & CATCTTGTCCGAAACGTCGAT & CCCTTCGAACATACACCTCCA & 101 \\
\hline SCD1 & AY241933 & TCCTGTTGTTGTGCTTCATCC & GGCATAACGGAATAAGGTGGC & 101 \\
\hline AGPAT6 & DY208485 & AAGCAAGTTGCCCATCCTCA & AAACTGTGGCTCCAATTTCGA & 101 \\
\hline $18 S$ & NR036642 & GCCCGAAGCGTTTACTTTGA & TTCCATTATTCCTAGCTGCGGTAT & 82 \\
\hline
\end{tabular}

PPAR y, proliferator-activated receptor gamma; FABP4, fatty acid-binding protein 4; C/EBPa, CCAAT/enhancer binding protein a; HSL, hormone-sensitive lipase; ATGL, adipose triglyceride lipase; FASN, fatty acid synthetase; ACACA, acetyl-coa carboxylase; SCD1, stearoyl-CoA desaturase 1; AGPAT6, 1-acylglycerol-3-phosphate 0-acyltransferase.

Table 3. Effects of photoperiod on growth performance of Jinjiang cattle

\begin{tabular}{lccc}
\hline Items & Control & Treatment & p-value \\
\hline Average daily gains (ADG, kg/d) & $0.369 \pm 0.036$ & $0.456 \pm 0.063$ & 0.245 \\
Dry matter intake (DMl, kg/d) & $5.49 \pm 0.19^{\mathrm{b}}$ & $6.34 \pm 0.20^{\mathrm{a}}$ & 0.007 \\
F/G (DMl/ADG) & $14.89 \pm 0.6$ & $13.90 \pm 0.8$ & 0.337 \\
\hline
\end{tabular}

Data has been expressed as the mean \pm standard error of the mean $(n=9)$.

Means within a row with common superscripts do not differ $(p>0.05)$.

Student's t-test were performed to compare the values between the groups and significant differences were represented with different letters $\left(\left(^{a, b}\right)\right.$. 


\section{RESULTS}

\section{Growth performance}

The possible effects of light on the growth performance of Jinjiang cattle are shown in Table 3. Interestingly, the cattle held under photoperiods of $16 \mathrm{~h}$ of light/d showed significantly increased dry matter intake (DMI) compared to the cattle held under NP $(\mathrm{p}<0.05)$; however, no significant differences were observed of average daily gain (ADG) and F/G (DMI/ADG) in both the LP and NP groups.

\section{Blood lipid metabolism related indicators}

The effects of prolonged photoperiod on the blood lipid metabolism of Jinjiang cattle are shown in Table 4. We found that the Glu and TC levels in the treatment group were significantly reduced $(\mathrm{p}<0.001)$ but TG and other indexes were not significantly affected ( $>00.05)$. The ApoE levels in the experimental group were significantly increased $(\mathrm{p}<0.001)$.

\section{Plasma hormone levels}

The effects of prolonged photoperiod treatment in winter on the blood lipid metabolism related hormone levels in Jinjiang cattle are shown in Figure 1. Interestingly, melatonin levels were found to be lower during the daytime but higher at night in control and the treatment groups; melatonin levels in LP group were noted to be significantly lower than the control group at 6:00 and 22:00 $(\mathrm{p}<0.05)$. Moreover, it was observed that melatonin level decline was significantly higher in LP than those in NP group at 6:00. The levels of leptin were also significantly reduced $(\mathrm{p}<0.05)$ and insulin levels were found to be higher in LP group than in NP group ( $\mathrm{p}<$ $0.05)$.

\section{Carcass traits and meat quality}

The possible effects of the prolonged photoperiod carcass traits and meat quality of Jinjiang bulls are respectively shown in Table 5 and 6 . The backfat thickness was found to be significantly higher in LP $(\mathrm{p}<0.001)$. There were no significant differences in $\mathrm{BFM}$ in meat quality at $\mathrm{pH}_{45 \text { min }}$, cooking loss, shear force and meat color $\left(\mathrm{L}^{*}\right.$ and $\left.\mathrm{b}^{*}\right)$ between the LP and NP groups ( $p>0.05)$. However, LDM in LP group displayed a significantly lower redness $(\mathrm{p}<0.05)$. In addition, the dripping loss of BFM increased significantly when cattle were exposed in LP $(\mathrm{p}<0.05)$. The possible effects of prolonged photoperiod on conventional nutrients content of Jinjiang cattle are shown in Table 7. It was found that a relatively longer photoperiod significantly increased the crude fat of the BFM in LP $(p<0.05)$, but there was no significant difference observed both in the dry matter content and crude protein content in BFM and LDM ( $\mathrm{p}>0.05)$.

\section{Fatty acid profile}

The effects of prolonged photoperiod on fatty acid composition are shown in Table 8. The fatty acid composition of IMF in $\mathrm{LDM}$ from a prolonged light time up to $16 \mathrm{~h}$ was measured. It was found that the levels of C17:0 and C18:0 were significantly increased $(\mathrm{p}<0.05)$, while the levels of $\mathrm{C} 16: 1$ were significantly decreased $(p<0.05)$. However, C18:1 level was not significantly affected between the LP and NP groups ( $p>0.05$ ), the proportions of saturated fatty acids, monounsaturated fatty acids (MUFA), and polyunsaturated fatty acids (PUFA) showed no significant differences between the LP and NP groups ( $\mathrm{p}>0.05)$.

\section{Relative mRNA expression}

The relative mRNA expression levels of lipid synthesis related genes proliferator-activated receptor gamma $(P P A R \gamma)$ and fatty acid-binding protein (FABP4) in IMF of LDM were significantly higher $(\mathrm{p}<0.05)$ than those in NP. However, the level of hormone-sensitive lipase (HSL) gene was significantly decreased $(\mathrm{p}<0.05)$. The fatty acid synthesis gene acetyl-coa carboxylase (ACACA), fatty acid synthetase (FASN), and 1-acylglycerol-3-phosphate O-acyltransferase (AGPAT-6) genes were also significantly increased in LP $(\mathrm{p}<0.05)$. The relative mRNA expression of stearoyl-CoA desaturase 1 $(S C D 1)$ were significantly decreased $(\mathrm{p}<0.05)$. CCAAT/en-

Table 4. Effects of photoperiod on serum lipid metabolism index of Jinjiang cattle

\begin{tabular}{lcrr}
\hline Items & Control & Treatment & p-value \\
\hline Glucose $(\mathrm{ng} / \mathrm{L})$ & $5.100 \pm 0.127^{\mathrm{a}}$ & $4.450 \pm 0.067^{\mathrm{b}}$ & 0.044 \\
Total cholesterol (mmol/L) & $5.463 \pm 0.150^{\mathrm{a}}$ & $<.377 \pm 0.048^{\mathrm{b}}$ & 0.001 \\
Triglycerides (mmol/L) & $0.290 \pm 0.025$ & $0.293 \pm 0.016$ & 0.993 \\
Non-esterified fatty acids (mmol/L) & $0.180 \pm 0.006$ & $0.190 \pm 0.006$ & 0.976 \\
High-density lipoprotein (mmol/L) & $2.630 \pm 0.158$ & $2.423 \pm 0.034$ & 0.518 \\
Low-density lipoprotein (mmol/L) & $0.397 \pm 0.014$ & $0.367 \pm 0.013$ & 0.926 \\
Apolipoprotein A1 (g/L) & $0.060 \pm 0.003$ & $0.043 \pm 0.002$ & 0.958 \\
Apolipoprotein B (g/L) & $0.025 \pm 0.001$ & $0.021 \pm 0.002$ & 0.990 \\
Apolipoprotein E (mg/L) & $11.33 \pm 0.211^{\mathrm{b}}$ & $16.67 \pm 0.211^{\mathrm{a}}$ & $<0.001$ \\
\hline
\end{tabular}

Data are expressed as the mean \pm standard error of the mean $(n=6)$.

Means within a row with common superscripts do not differ $(p>0.05)$. Student's t-test were performed to compare the values between the groups and significant differences were represented with different letters $\left({ }^{a, b}\right)$. 

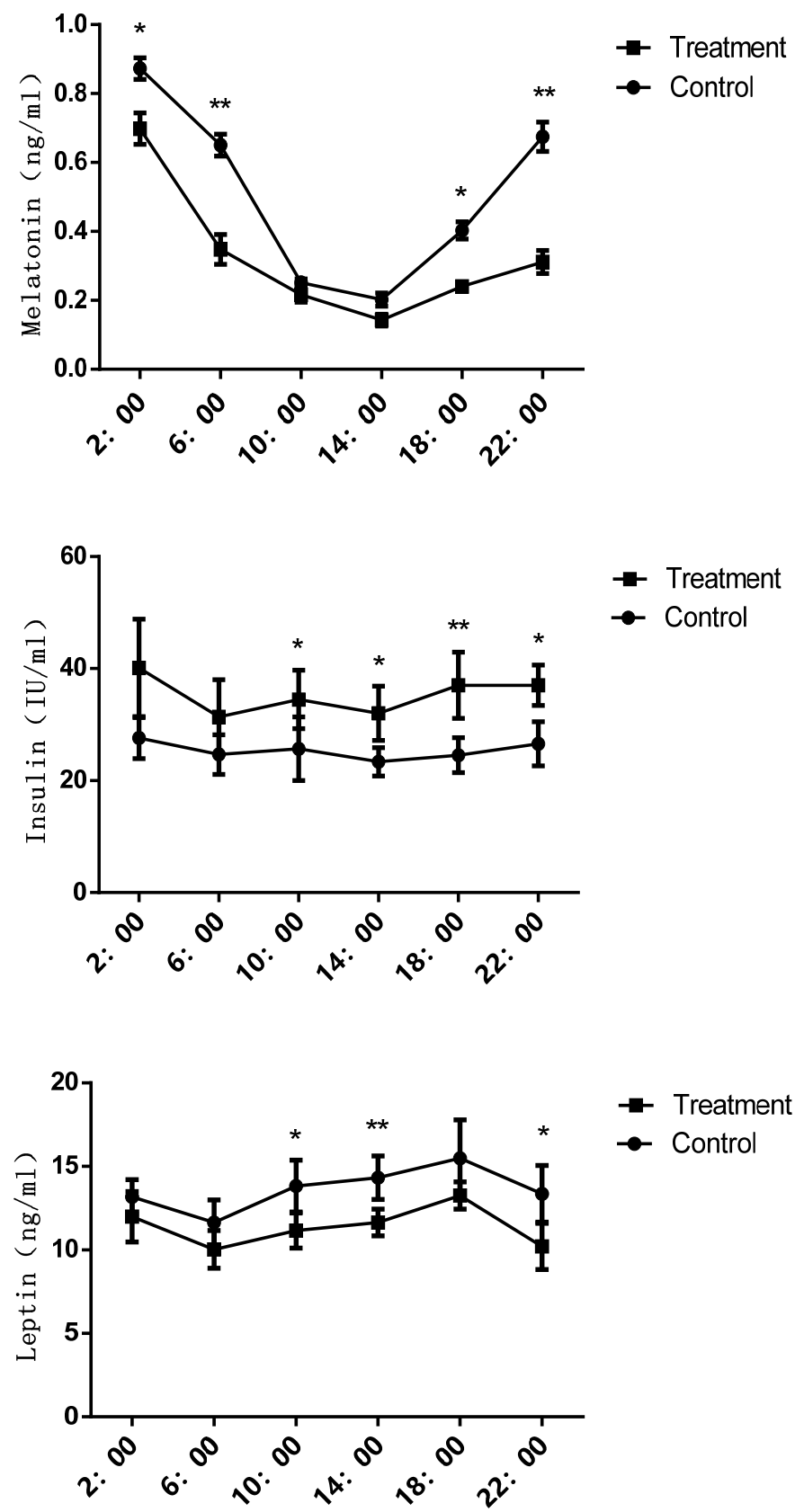

Figure 1. Effects of prolonged photoperiod on blood lipid metabolism related hormone levels in Jinjiang cattle in winter. The data has been shown as the mean \pm standard error of six replicates, * and $* *$ mean values within different letters were significantly different $(p<0.05)$ and $(p<0.01)$.

Table 5. Effects of prolonged photoperiod carcass traits of Jinjiang cattle

\begin{tabular}{lccc}
\hline Traits & Control & Treatment & p-value \\
\hline Marbling score & $2.07 \pm 0.201$ & $2.50 \pm 0.224$ & 0.183 \\
Eye muscle area $\left(\mathrm{cm}^{2}\right)$ & $95.28 \pm 3.118$ & $86.74 \pm 2.993$ & 0.066 \\
Backfat thickness $(\mathrm{cm})$ & $1.96 \pm 0.392^{\mathrm{b}}$ & $3.06 \pm 0.460^{\mathrm{a}}$ & $<0.001$ \\
\hline
\end{tabular}

Data are expressed as the mean \pm standard error of the mean $(n=6)$.

a,b Means within a row with common superscripts do not differ $(p>0.05)$. Student's t-test were performed to compare the values between the groups and significant differences were represented with different letters. hancer binding protein $(C / E B P \alpha)$ and adipose triglyceride lipase $(A T G L)$ were found to be not significantly different between the LP and NP groups ( $\mathrm{p}>0.05$ ) (Figure 2).

\section{DISCUSSION}

The potential effects of photoperiod on the growth performance and blood lipid metabolism related indicators

The length of photoperiod usually plays an important role in 
Table 6. Effects of prolonged photoperiod on fleshy characteristics of Jinjiang cattle

\begin{tabular}{lllccc}
\hline Traits & Position & Control & Treatment & p-value \\
\hline $\mathrm{pH}_{45 \text { min }}$ & & Biceps femoris muscle & $5.516 \pm 0.101$ & $5.442 \pm 0.081$ & 0.569 \\
Shear force (/kgf) & & Dorsi longus muscle & $5.419 \pm 0.112$ & $5.281 \pm 0.133$ & 0.433 \\
& & Biceps femoris muscle & $3.907 \pm 0.236$ & $3.944 \pm 0.157$ & 0.897 \\
Dripping loss (\%) & & Dorsi longus muscle & $3.594 \pm 0.108$ & $3.775 \pm 0.127$ & 0.288 \\
& & Biceps femoris muscle & $3.035 \pm 0.265^{b}$ & $4.498 \pm 0.364^{\mathrm{a}}$ & 0.004 \\
Cooking loss (\%) & & Dorsi longus muscle & $3.636 \pm 0.224$ & $4.292 \pm 0.224$ & 0.051 \\
& & Biceps femoris muscle & $29.7 \pm 1.810$ & $33.72 \pm 1.63$ & 0.109 \\
Meat color & & Dorsi longus muscle & $28.4 \pm 2.010$ & $29.4 \pm 1.621$ & 0.694 \\
& $L^{*}$ & Biceps femoris muscle & $39.78 \pm 0.597$ & $40.03 \pm 0.569$ & 0.768 \\
& $a^{*}$ & & $18.96 \pm 0.128$ & $18.71 \pm 0.122$ & 0.188 \\
& $b^{*}$ & & $8.700 \pm 0.127$ & $8.533 \pm 0.131$ & 0.381 \\
& $L^{*}$ & Dorsi longus muscle & $39.70 \pm 0.416$ & $39.87 \pm 0.470$ & 0.796 \\
& $a^{*}$ & & $18.93 \pm 0.101^{a}$ & $18.38 \pm 0.188^{b}$ & 0.028 \\
\end{tabular}

Data are expressed as the mean \pm standard error of the mean $(n=6)$.

$L^{\star}$, lightness; $a^{\star}$, redness; $b *$, yellowness.

Means within a row with common superscripts do not differ $(p>0.05)$

Student's t-test were performed to compare the values between the groups and significant differences were represented with different letters $\left({ }^{a, b}\right)$

Table 7. Effects of prolonged photoperiod on conventional nutrients content of Jinjiang cattle

\begin{tabular}{llcrc}
\hline Items & Position & Control & Treatment & p-value \\
\hline Dry matter (\%) & Biceps femoris muscle & $24.29 \pm 0.208$ & $24.61 \pm 0.421$ & 0.510 \\
& Dorsi longus muscle & $26.55 \pm 0.673$ & $25.52 \pm 0.307$ & 0.182 \\
Crude fat \% DM & Biceps femoris muscle & $4.25 \pm 0.294^{\mathrm{b}}$ & $5.36 \pm 0.355^{\mathrm{a}}$ & 0.037 \\
& Dorsi longus muscle & $6.72 \pm 0.257$ & $7.78 \pm 0.403$ & 0.051 \\
Crude protein \% DM & Biceps femoris muscle & $23.47 \pm 0.202$ & $23.52 \pm 0.109$ & 0.832 \\
& Dorsi longus muscle & $23.41 \pm 0.310$ & $22.71 \pm 0.255$ & 0.112 \\
\hline
\end{tabular}

DM, dry matter.

Data are expressed as the mean \pm standard error of the mean $(n=6)$.

a,b Means within a row with common superscripts do not differ $(p>0.05)$

Student's t-test were performed to compare the values between the groups and significant differences were represented with different letters.

the growth, food intake and metabolism rhythm of animals $[11,18,19,20]$. Sheep exposed to a change from LP to SP reduce voluntary food intake [21]. However, extending the photoperiod for cattle in winter reduced body fatness in both steers and heifers and increased the time heifers spend lying down but that there were no major effects on growth rate or food intake [9]. In our experiments, it was found that the cattle held under LP showed significantly increased DMI relative to NP. However no significant differences were observed in $\mathrm{ADG}$ and $\mathrm{F} / \mathrm{G}$. This result was not consistent with previous study, which might due to different animal species or their physiological stage.

These results indicates that a longer photoperiod may affect the appetite levels and energy metabolism of Jinjiang cattle.

A number of previous studies have shown that Phodopus sungorus $x$ appetite and body adiposity can substantially increase with associated central leptin insensitivity during a LP [22]. Leptin, which is mainly expressed and secreted by adipocytes, functions in the control of body mass through exerting its potential effects on both energy intake and energy expenditure [23]. Serum leptin concentration has been reported to dramatically decrease during winter-like acclimation, accompanied by an increase in energy intake in Brandt's voles [24]. Furthermore, leptin receptors $\mathrm{Ob}-\mathrm{Ra}$ and $\mathrm{Ob}-\mathrm{Rb}$ mRNA were higher under long DL in lactating and pregnant Holstein cows [25]. As a result, the increased DMI may be due to hormonal regulation, in addition, it may also be caused by increased fat deposition that requires more energy.

Different hormones (such as insulin, leptin and melatonin) have been found to be closely associated with regulating lipid metabolism, and their content in the body may be directly or indirectly affected by the photoperiod [23]. In addition, both leptin and insulin levels may not only be directly affected by photoperiod, but can be also regulated by dietary energy levels and melatonin [26]. The activation of melatonin receptor 1 signaling at night can modulate insulin sensitivity during the day via the regulation of the phosphatidylinositol 3 -kinase transcription and activity in mice [27]. Moreover, in Fischer 344 rats exposed to a SP of $6 \mathrm{~h}$ light/d showed an 
Table 8. Fatty acid composition (\% of total fatty acids) in intramuscular fat of Jinjiang cattle

\begin{tabular}{|c|c|c|c|}
\hline Items & Control & Treatment & p-value \\
\hline C10:0 Capric acid & $0.04 \pm 0.012$ & $0.046 \pm 0.010$ & 0.709 \\
\hline C12:0 Lauric acid & $0.051 \pm 0.008$ & $0.053 \pm 0.005$ & 0.788 \\
\hline C13:0 Tridecanoic acid & $0.020 \pm 0.006$ & $0.013 \pm 0.004$ & 0.384 \\
\hline C14:0 Myristic acid & $1.870 \pm 0.262$ & $1.530 \pm 0.201$ & 0.327 \\
\hline C15:0 Pentadecanoic acid & $0.341 \pm 0.029$ & $0.310 \pm 0.037$ & 0.538 \\
\hline C16:0 Palmitic acid & $25.722 \pm 1.124$ & $25.270 \pm 1.251$ & 0.794 \\
\hline C17:0 Heptadecanoic acid & $1.660 \pm 0.081^{b}$ & $1.880 \pm 0.051^{\mathrm{a}}$ & 0.044 \\
\hline C18:0 Stearic acid & $17.200 \pm 0.782^{b}$ & $19.740 \pm 0.793^{\mathrm{a}}$ & 0.047 \\
\hline C20:0 Arachidic acid & $0.261 \pm 0.017$ & $0.402 \pm 0.161$ & 0.407 \\
\hline C14:1 Myristoleic acid & $0.174 \pm 0.089$ & $0.231 \pm 0.100$ & 0.663 \\
\hline C15:1 Pentadecenoic acid & $0.151 \pm 0.060$ & $0.280 \pm 0.082$ & 0.229 \\
\hline C16:1 Palmitoleic acid & $1.480 \pm 0.121^{\mathrm{a}}$ & $1.060 \pm 0.120^{b}$ & 0.033 \\
\hline C17:1 Heptadecenoic acid & $0.260 \pm 0.089$ & $0.320 \pm 0.061$ & 0.590 \\
\hline C18:1 Oleic acid & $41.210 \pm 2.110$ & $41.699 \pm 2.090$ & 0.872 \\
\hline C20:1n9 Eicosenoic acid & $0.141 \pm 0.078$ & $0.162 \pm 0.609$ & 0.975 \\
\hline C22:1n9 Erucic acid & $0.069 \pm 0.004$ & $0.088 \pm 0.008$ & 0.064 \\
\hline C18:2n Linoleic acid & $6.890 \pm 0.430$ & $5.100 \pm 0.681$ & 0.051 \\
\hline C18:3n3 y-Linolenic acid & $1.320 \pm 0.152$ & $0.880 \pm 0.249$ & 0.971 \\
\hline C18:3n6 a-Linolenic acid & $0.491 \pm 0.209$ & $0.420 \pm 0.301$ & 0.852 \\
\hline C20:3 Eicosatrienoic acid & $0.041 \pm 0.023$ & $0.041 \pm 0.009$ & 0.968 \\
\hline C20:4 Arachidonic acid & $0.025 \pm 0.002$ & $0.020 \pm 0.002$ & 0.054 \\
\hline C20:5 Eicosapentaenoic acid & $0.181 \pm 0.029$ & $0.187 \pm 0.018$ & 0.842 \\
\hline C22:6 Docosahexaenoic acid & $0.012 \pm 0.003$ & $0.015 \pm 0.003$ & 0.482 \\
\hline SFA & $47.252 \pm 5.125$ & $49.316 \pm 5.629$ & 0.274 \\
\hline MUFA & $43.489 \pm 4.231$ & $43.832 \pm 2.022$ & 0.176 \\
\hline PUFA & $8.959 \pm 2.152$ & $6.662 \pm 1.651$ & 0.417 \\
\hline
\end{tabular}

SFA, saturated fatty acids; MUFA, monounsaturated fatty acids; PUFA, polyunsaturated fatty acids.

Data are expressed as the mean \pm standard error of the mean $(n=6)$.

Means within a row with common superscripts do not differ $(p>0.05)$.

Student's t-test were performed to compare the values between the groups and significant differences were represented with different letters $\left({ }^{a, b}\right)$.

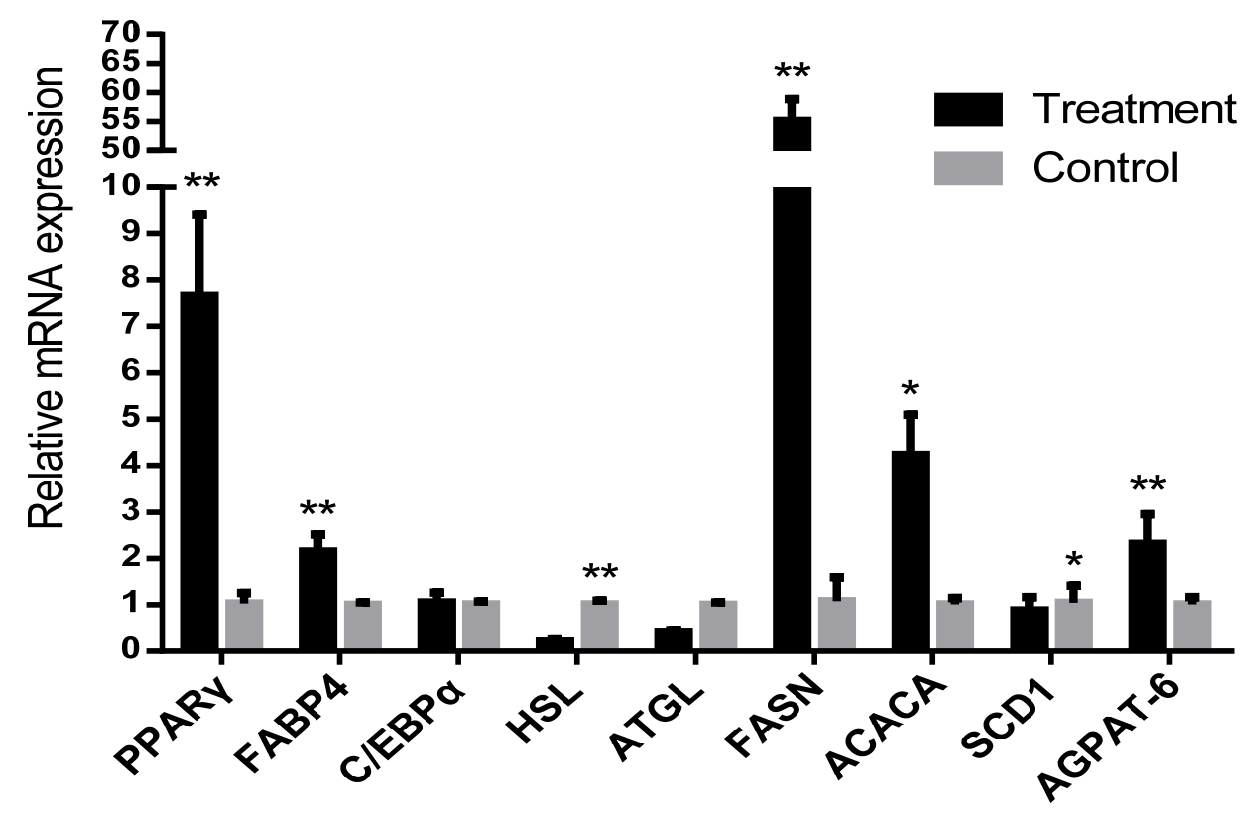

Figure 2. Relative mRNA expressions of lipid metabolism-related genes were normalized to 18s gene expression. The data has been shown as the mean \pm standard error of six replicates, ${ }^{*}$ and ${ }^{* *}$ mean values within different letters were significantly different $(p<0.05)$ and $(p<0.01)$. 
increased level of Glu and NEFA. The downstream post-receptor target of insulin was significantly down-regulated in $6 \mathrm{~h} \mathrm{light/d}$ as compared to the $12 \mathrm{~h}$ light/d [28]. The lower Glu and the higher insulin level indicate that insulin can improve Glu utilization and enhance anabolism while significantly reducing the mobilization of body fat decomposition in the cold winter. Additionally, bulls' backfat thickness was significantly increased the prolonged photoperiod treatment, which might be beneficial to withstand the low temperature for Jinjiang cattle. Moreover, pigs exposed to the longer photoperiod showed a greater tendency towards a higher slaughtering body weight and a higher saturation degree of subcutaneous fat in the raw thighs [29]. This suggests that fat deposition could also increase in Jinjiang cattle during the prolonged photoperiod treatment. Insulin can promote fat synthesis, whereas leptin may exert opposite effects. Hormonal changes noticed were generally consistent with the fat deposition, and these observations suggested that exposure to the longer photoperiod may regulate hormone levels thereby promoting fat deposition.

\section{Effect of photoperiod on meat quality of Jinjiang beef in winter}

The BFM predominantly can control the activities of cattle, which are mainly affected by the amount of activity. Our previous study reported that the activity of Jinjiang cattle decreased with the rest time increased in LP group. The LDM can be used in high-end steaks, and the meat quality may be primarily affected by the dietary energy. Therefore, the effect of photoperiod on meat quality of these two different parts may be worth exploring in future studies. The longer photoperiod substantially increased the dipping loss in the BFM of Jinjiang cattle, but it had no significant effect on the LDM.

At 45 min after slaughter, the $\mathrm{a}^{\star}$ value of the LP group was found to be significantly lower in LDM of Jinjiang cattle, however no significant changes were noted in the meat color of BFM. Previous studies in broiler chickens reported that muscles from $20 \mathrm{~L}: 4 \mathrm{D}$ appeared to be lighter and more discolored, coupled with higher lipid oxidation and protein denaturation as compared to $12 \mathrm{~L}: 12 \mathrm{D}[30,31]$. The broilers subjected to $23 \mathrm{~L}: 1 \mathrm{D}$ and $16 \mathrm{~L}: 8 \mathrm{D}$ had maximum fat and least protein [7]. It has also been reported that the contents of fat and protein of the loin from castrated crossbred ideal male lambs exposed to the LP were significantly affected. The water-holding capacity of the loin was found to be lowest when the animals were exposed to a LP, while no significant differences were observed for water-biding capacity and cooking losses [32]. Moreover, pigs in the LP group displayed a greater live weight and carcass weight as compared to the SP group; hams obtained from the LP group were significantly heavier and their weight losses during the dry-curing period were noted to be significantly reduced when compared to the SP group [6]. All the above results suggest that changes in meat quality may be significantly related to the muscle location and the species of the animal.

Although the muscle crude fat was increased, the meat quality was not significant changed. It may be due to the short feeding cycle and the amount of fat deposited is not at a level that significantly changes the meat quality. In addition, the measurement sample size is small, and the error is large. What is exciting to us is that the LP increases the muscle fat content, which is still significant in beef cattle production, but the effect on meat quality may need to be further verified by more experiments.

\section{Effect of photoperiod on fatty acid composition and} the expression of genes related to lipid metabolism The main MUFAs found in beef include C16:1 and C18:1, and main PUFAs are C18:2, C18:3, C20:4 [33]. Among the MUFAs, C18:1 has been primarily found to be a useful indicator for meat quality because of its association with beef palatability [34]. When Jinjiang cattle were raised in the LP, the levels of C17:0 and C18:0 were found to be significantly increased, while the levels of C16:1 were significantly decreased. Although the photoperiod had no significant effect on levels of C16:0 and C18:1, the level of C18:1 was higher in LP group. These findings indicated that Photoperiod could improve the fatty acid composition of Jinjiang cattle to some extent, and LP improved the flavor quality of Jinjiang beef substantially.

The SCD exists in adipose tissue and has been reported to be involved in cellular metabolism and the differentiation of precursor adipocytes. The amount of IMF content and the proportion of MUFA can increase spectacularly in grain-fed cattle with time on feed in relation to the activity of $S C D$ [35]. The increased levels of C18:0 might be associated with the down-regulated SCD1 in LP group. ACACA and FASN are the key regulatory enzymes involved in the lipid synthesis process. The relative mRNA expressions of FASN and ACACA genes were up-regulated in LP, and promoted the synthesis of fatty acids. In addition, therefore, photoperiod may mediate the expression of related genes to regulate fatty acid composition.

Changes in photoperiod length are transduced into neuroendocrine signals by melatonin secreted by the pineal gland triggering seasonally adaptive responses in many animal species. Siberian hamsters, transferred from a long-day 'summer-like' photoperiod to a short-day 'winter-like' photoperiod, exhibit a naturally occurring reversal in obesity [36]. Insulin, leptin and melatonin have all been reported to regulate lipid metabolism by controlling the expression of related genes, and some research showed that melatonin inhibits fat synthesis by reducing the mRNA expression level of key genes such as $P P A R \gamma, C / E B P \alpha$, and $C / E B P \beta$ of fat 
synthesis in mouse 3T3-L1 preadipocytes [37].

The relative mRNA expressions of lipid synthesis genes of $P P A R \gamma, F A B P 4$, and AGPAT has been associated with TG synthesis which were similarly up regulated upon exposure to LP. The lipid hydrolysis gene HSL was significantly downregulated in LP. This finding also suggested the possibility of the increased fat synthesis and reduced lipolysis at the molecular level in the cold environment.

There are two possible reasons for LP promoting fat deposition in Jinjiang cattle. On the one hand, LP may increase DMI and directly promote the expression of genes related to fat deposition. On the other hand, LP can directly or indirectly regulate the expression of genes related to lipid metabolism through hormones.

In this study, the effects of LP on the characteristics of lipid metabolism and related mechanisms of growth performance of Jinjiang cattle were preliminarily investigated, but the specific mechanisms are worth further investigation.

\section{CONCLUSION}

Prolonged photoperiod had no significant effect on the growth performance and meat quality of Jinjiang cattle, however it showed a certain improvement trend. The LP significantly increased the muscle fat deposition level, which is of great significance in beef cattle production. This study provided a certain scientific basis for photoperiod management of Jinjiang cattle in winter.

\section{CONFLICT OF INTEREST}

We certify that there is no conflict of interest with any financial organization regarding the material discussed in the manuscript.

\section{ACKNOWLEDGMENTS}

Yu Yan benefited from the National Key R\&D Plan (grant number 2016YFD0500508) for funding this work. We are grateful to the Jiangsu Collaborative Innovation Center of Meat Production and Processing for the test of meat quality.

\section{REFERENCES}

1. Beatty D, Barnes A, Pethick DW, Taylor E, Dunshea FR. Bos indicus cattle can maintain feed intake and fat reserves in response to heat stress better than Bos taurus cattle. J Anim Feed Sci 2004;13(Suppl 1):619-22.

2. Jin YY, Yang $Q$, Zhang $M$, et al. Identification of a novel polymorphism in bovine lncRNA ADNCR gene and its association with growth traits. Anim Biotechnol 2019;30:159-65. https:// doi.org/10.1080/10495398.2018.1456446
3. Luo D, Gao YF, Lu YY, et al. Niacin supplementation improves growth performance and nutrient utilisation in Chinese Jinjiang cattle. Ital J Anim Sci 2019;18:57-62. https://doi. org/10.1080/1828051X.2018.1480426

4. Liang H, Zhao EL, Feng CY, et al. Effects of slow-release urea on in vitro rumen fermentation parameters, growth performance, nutrient digestibility and serum metabolites of beef cattle. Semin Cienc Agrar 2020;41:1399-414.

5. Martelli G, Nannoni E, Grandi M, et al. Growth parameters, behavior, and meat and ham quality of heavy pigs subjected to photoperiods of different duration. J Anim Sci 2015;93: 758-66. https://doi.org/10.2527/jas.2014-7906

6. Baykalir Y, Simsek UG, Erisir M, et al. Photoperiod effects on carcass traits, meat quality, and stress response in heart and lung of broilers. S Afr J Anim Sci 2020;50:138-49. https:// doi.org/10.4314/sajas.v50i1.15

7. Dahl GE, Petitclerc D. Management of photoperiod in the dairy herd for improved production and health. J Anim Sci 2003;81:11-7. https://doi.org/10.2527/2003.81suppl_311x

8. Phillips CJC, Johnson PN, Arab TM. The effect of supplementary light during winter on the growth, body composition and behaviour of steers and heifers. Anim Sci 1997;65: 173-81. https://doi.org/10.1017/s1357729800016477

9. Mendieta ES, Delgadillo JA, Flores JA, et al. Subtropical goats ovulate in response to the male effect after a prolonged treatment of artificial long days to stimulate their milk yield. Reprod Domest Anim 2018;53:955-62. https://doi.org/10. 1111/rda.13194

10. Miller ARE, Stanisiewski EP, Erdman RA, Douglass LW, Dahl GE. Effects of long daily photoperiod and bovine somatotropin (Trobest ${ }^{\bullet}$ ) on milk yield in cows. J Dairy Sci 1999;82:1716-22. https://doi.org/10.3168/jds.S0022-0302 (99)75401-9

11.de Almeida GLP, Pandorfi H, Baptista F, Guiselini C, da Cruz VF, de Almeida GAP. Efficiency of use of supplementary lighting in rearing of dairy calves during milk feeding stage. Rev Bras Eng Agric Ambient 2015;19:989-95.

12.de Almeida GLP, Pandorfi H, Baptista F, Guiselini C, Ferreira $\mathrm{MD}$, Cruz VF. Concentrate intake and performance of dairy calves subjected to programs of supplementary lighting. Cienc Rural 2017;47: e20160726. https://doi.org/10.1590/0103$8478 \mathrm{cr} 20160726$

13. Mikolayunas CM, Thomas DL, Dahl GE, Gressley TF, Berger YM. Effect of prepartum photoperiod on milk production and prolactin concentration of dairy ewes. J Dairy Sci 2008; 91:85-90. https://doi.org/10.3168/jds.2007-0586

14. Bernabucci U, Basirico L, Lacetera N, et al. Photoperiod affects gene expression of leptin and leptin receptors in adipose tissue from lactating dairy cows. J Dairy Sci 2006;89:467886. https://doi.org/10.3168/jds.S0022-0302(06)72518-8

15. Bentley PA, Wall EH, Dahl GE, McFadden TB. Responses of the mammary transcriptome of dairy cows to altered photo- 
period during late gestation. Physiol Genomics 2015;47:48899. https://doi.org/10.1152/physiolgenomics.00112.2014

16. Yin BJ, Li TT, Li Z, Dang T, He PL. Determination of melatonin and its metabolites in biological fluids and eggs using high-performance liquid chromatography with fluorescence and quadrupole-orbitrap high-resolution mass spectrometry. Food Anal Methods 2016;9:1142-9. https://doi.org/10.1007/ s12161-015-0288-2

17.Zheng Y, Wang SZ, Yan PS. The meat quality, muscle fiber characteristics and fatty acid profile in Jinjiang and F1 Simmental $\times$ Jinjiang yellow cattle. Asian-Australas J Anim 2018;31:301-8. https://doi.org/10.5713/ajas.17.0319

18. Concannon P, Levac K, Rawson R, Tennant B, Bensadoun A. Seasonal changes in serum leptin, food intake, and body weight in photoentrained woodchucks. Am J Physiol Regul Integr Comp Physiol 2001;281:R951-9.

19. Ciocan H, Imhof A, Marco MVP, Isberg SR, Siroski PA, Larriera A. Increasing photoperiod enhances growth in captive hatchling Caiman latirostris. Aquaculture 2018;482:193-6. https://doi.org/10.1016/j.aquaculture.2017.10.002

20. Marie M, Findlay PA, Thomas L, Adam CL. Daily patterns of plasma leptin in sheep: effects of photoperiod and food intake. J Endocrinol 2001;170:277-86. https://doi.org/10. 1677/joe.0.1700277

21. Kokolski M, Ebling FJ, Henstock JR, Anderson SI. Photoperiod-induced increases in Bone Mineral apposition rate in siberian hamsters and the involvement of seasonal leptin changes. Front Endocrinol 2017;8:357. https://doi.org/10. 3389/fendo.2017.00357

22. Bartness TJ, Demas GE, Song CK. Seasonal changes in adiposity: the roles of the photoperiod, melatonin and other hormones, and sympathetic nervous system. Exp Biol Med 2002;227:363-76. https://doi.org/10.1177/153537020222 700601

23.Zhang XY, Wang DH. Energy metabolism, thermogenesis and body mass regulation in Brandt's voles (Lasiopodomys brandtii) during cold acclimation and rewarming. Horm Behav 2006;50:61-9. https://doi.org/10.1016/j.yhbeh.2006. 01.005

24. Bernabucci U, Basirico L, Lacetera N, et al. Photoperiod affects gene expression of leptin and leptin receptors in adipose tissue from lactating dairy cows. J Dairy Sci 2006;89:467886. https://doi.org/10.3168/jds.S0022-0302(06)72518-8

25. Ross AW, Russell L, Helfer G, Thomson LM, Dalby MJ, Morgan PJ. Photoperiod regulates lean mass accretion, but not adiposity, in growing F344 rats fed a high fat diet. Plos One 2015;10: e0119763. https://doi.org/10.1371/journal.pone.0119763

26. Owino S, Sanchez-Bretano A, Tchio CT, et al. Nocturnal activation of melatonin receptor type 1 signaling modulates diurnal insulin sensitivity via regulation of PI3K activity. J Pineal Res 2018;64: e12462. https://doi.org/10.1111/jpi.12462

27. Marine-Casado R, Domenech-Coca C, del Bas JM, Blade C, Arola L, Caimari A. The exposure to different photoperiods strongly modulates the glucose and lipid metabolisms of normoweight fischer 344 rats. Front Physiol 2018;9:416. https://doi.org/10.3389/fphys.2018.00416

28. Sardi L, Nannoni E, Grandi M, Vignola G, Zaghini G, Martelli G. Meat and ham quality of Italian heavy pigs subjected to different illumination regimes. Berl Munch Tierarztl Wochenschr 2012;125:463-8. https://doi.org/10.2376/00059366-125-463

29. Tuell JR, Park JY, Wang WC, Cheng HW, Kim YHB. Functional/physicochemical properties and oxidative stability of ground meat from broilers reared under different photoperiods. Poult Sci 2020;99:3761-8. https://doi.org/10.1016/j. psj.2020.04.021

30.Tuell JR, Park JY, Wang WC, et al. Effects of photoperiod regime on meat quality, oxidative stability, and metabolites of postmortem broiler fillet ( $M$. Pectoralis major) muscles. Foods 2020;9:215. https://doi.org/10.3390/foods9020215

31. Klein MH, de Siqueira ER, Roca RO. Meat quality of feedlot castrated or intact male lambs exposed to two photoperiod lengths. Rev Bras Zootec 2006;35:1872-9.

32. McAfee AJ, McSorley EM, Cuskelly GJ, et al. Red meat consumption: an overview of the risks and benefits. Meat Sci 2010;84:1-13. https://doi.org/10.1016/j.meatsci.2009.08.029

33.Hwang YH, Joo ST. Fatty acid profiles, meat quality, and sensory palatability of grain-fed and grass-fed beef from Hanwoo, American, and Australian crossbred cattle. Korean J Food Sci Anim Resour 2017;37:153-61. https://doi.org/10. 5851/kosfa.2017.37.2.153

34.Smith DR. Preharvest food safety challenges in beef and dairy production. Microbiol Spectr 2018;4:47-68 https:// doi.org/10.1128/microbiolspec.PFS-0008-2015

35. Ryu V, Zarebidaki E, Albers HE, Xue B, Bartness TJ. Short photoperiod reverses obesity in Siberian hamsters via sympathetically induced lipolysis and Browning in adipose tissue. Physiol Behav 2018;190:11-20. https://doi.org/10. 1016/j.physbeh.2017.07.011

36. Karamitri A, Sadek MS, Journe AS, et al. O-linked melatonin dimers as bivalent ligands targeting dimeric melatonin receptors. Bioorg Chem 2019;85:349-56. https://doi.org/10. 1016/j.bioorg.2019.01.004

37. Acuna-Castroviejo D, Escames G, Venegas C, et al. Extrapineal melatonin: sources, regulation, and potential functions. Cell Mol Life Sci 2014;71:2997-3025. https://doi.org/10.1007/ s00018-014-1579-2 